\title{
COMMENTARY
}

\section{What Impact will the Changes Announced in USMLE have on Successful Matching of International Medical Graduates in Residency Programs in the United States?}

\author{
Rameez Sohail Rao, 'Sohail Rao²
}

1. Rameez Sohail Rao, Internal Medicine Resident, Orlando Health, Orlando, Florida, United States

2. Sohail Rao, President and Chief Executive Officer, DHR Health Institute for Research \& Development, Edinburg, Texas, United States

Correspondence to: Dr. Sohail Rao, Email: s.rao@dhr-rgv.com, ORCiD: 0000-0001-5027-999

\begin{abstract}
All international medical graduates intending to join an Accreditation Council for Graduate Medical Educationaccredited clinical residency programs must obtain certification from the Educational Commission for Foreign Medical Graduates. A pre-requisite for obtaining this certification is the need to graduate from a medical school listed in the World Directory of Medical Schools and to pass all three steps of United States Medical Licensing Examination (USMLE). While the outcome of all three steps is important and considered during the evaluation of an applicant for residency training in the United States, the numerical score of Step 1 has generally been considered as one of the most important metrics during this process. However, as of 2022, USMLE Step 1 will be scored on a Pass/Fail basis eliminating the advantage afforded to the international medical graduates who traditionally scored relatively high on this step of the exam. It is therefore imperative that to succeed in obtaining a competitive residency program in the United States, international medical graduates must consider acquiring additional experience and expertise in the areas of research, publications, clinical electives in the United States, networking with program participants, etc.
\end{abstract}

Keywords: USMLE Step 1, International Medical Graduates, Residency, United States

This is an Open Access article distributed under the terms of the Creative Commons Attribution Non-Commercial License (http:// creative commons. org/licenses/by-nc/4.0) which permits unrestricted non-commercial use, distribution, and reproduction in any medium, provided the original work is properly cited.

For year 2020, 37,256 residency positions were available in various specialties in the United States for which, 40,084 applicants submitted program choices. ${ }^{1}$ This was the highest number of residency positions offered for match under the National Resident Matching Program (NRMP). However, despite a very competitive environment, year 2020 was a banner year for IMG's for matching in US residency programs (Figure 1). In 2020, of the 12,074 IMG applicants who applied, 7,376 (61.1\%) successfully matched into US residency programs. However, will this gradual upward trend of IMG's acceptance into US residency program continue? This remains to be seen given the fact that as of January 01, 2022, a major change has been announced in Step 1 format of United States Medical Licensing Exam ${ }^{\circledR}$ (USMLE). ${ }^{2}$ The USMLE assesses a physician's ability to apply knowledge, concepts, and principles, and to demonstrate fundamental patient-centered skills, that are important in health and disease and that constitute the basis of safe and effective patient care. ${ }^{3}$ All domestic and international medical graduates are required to obtain USMLE certification to apply for residency training in the United States. It is comprised of three distinct steps which are depicted in Figure 2.

For years, the score of USMLE Step 1 has served as one of the many evaluation tools used by the residency programs to appraise applicants for the purposes of granting interviews. Both domestic and IMG's recognized the significance of USMLE Step 1 and made every effort to score high on this exam. Of equal significance is the score of USMLE Step 2 Clinical Knowledge (CK) which has served to moderate student's performance in USMLE Step 1 exam. Medical students who scored relatively below average in USMLE Step 1 exam but were able to improve their performance in USMLE Step 2 were deemed competitive and were afforded an advantage in their selection for interviews.

THE IMPENDING SHORTAGE OF PHYSICIANS AND THE IMPORTANCE OF IMG'S IN THE DELIVERY OF CLINICAL CARE IN UNITED STATES:

The relationship between demand and supply of qualified physicians to meet healthcare needs in the 


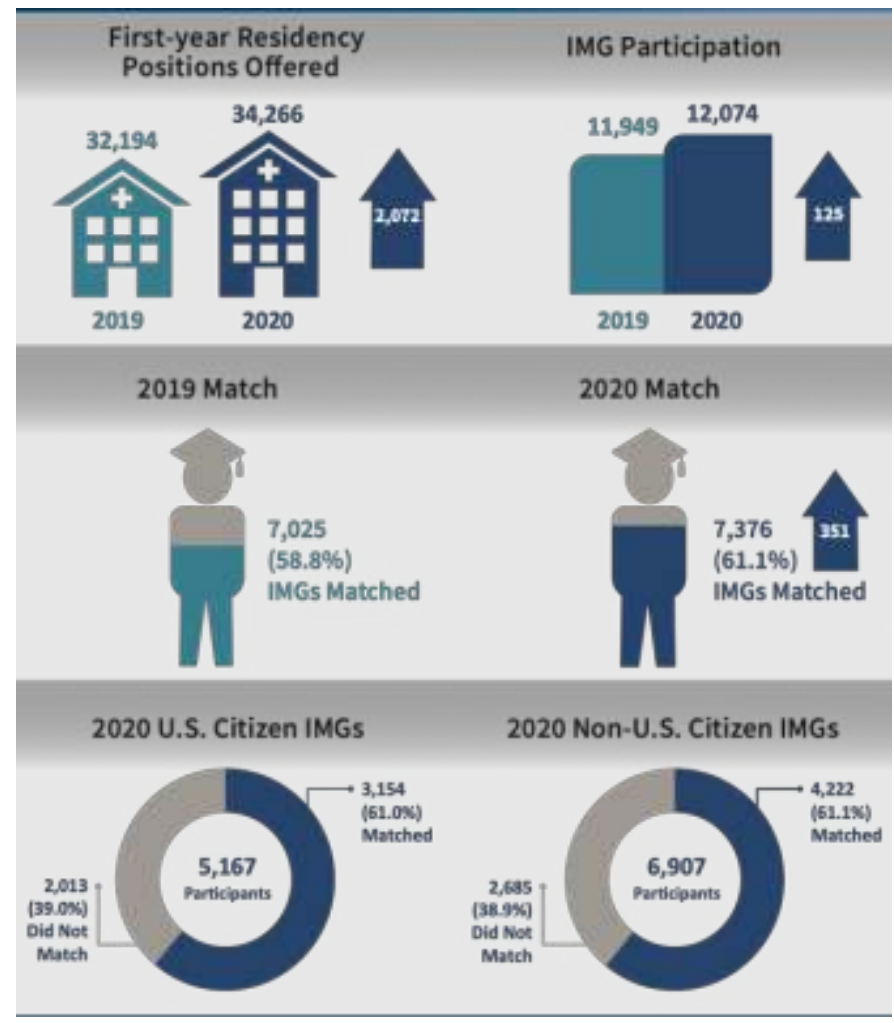

Figure 1: International Medical Graduates (IMG) Performance in the 2020 Main Residency Match (Source: National Residency Matching Program, Educational Commission for Foreign Medical Graduates).

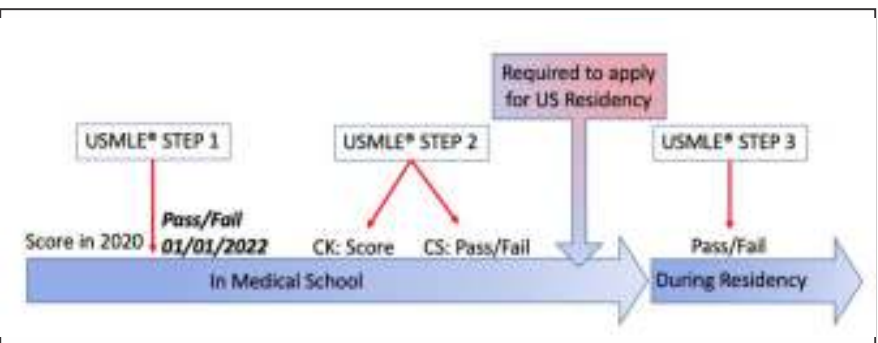

Figure 2: Various Stages of USMLE Exam and the Proposed Changes as of January 01, 2022. CK: Clinical Knowledge; CS: Clinical Skills

United States has been fiercely debated. ${ }^{4}$ In 2019, a report by the Association of American Medical Colleges (AAMC) suggested that currently, about 14,472 additional primary care physicians are required to meet the undersupply in identified shortage areas. With the expected shift in demographics due to growing population of people living longer, there will be an added demand for provision of healthcare services. It is projected that by 2032, United States will have a shortage from 46,900 to 121,900 physicians overall and from 21,100 to 55,000 primary care physicians. Further exaggerating this challenge is the projection that more than one-third of all physicians will be over the age of 65 years in the next decade and close to retirement. This J Dow Univ Health Sci 2020, Vol. 14 (3): 144-147 burgeoning physician shortage is more acute in rural communities where we have only 13.1 physicians and surgeons for every 10,000 residents as compared to 31.2 in urban areas. ${ }^{5}$

IMG's have always played a very important role in the delivery of quality clinical care and they constitute nearly a quarter of total GME pool and practicing physician workforce in the United States. ${ }^{6}$ Majority of IMG's practice in family medicine (32\%) and psychiatry (31\%), the two specialties that have been projected to see major shortages in United States in the future. In some specialties such as geriatrics and nephrology, IMG's make up approximately $50 \%$ of active physicians. ${ }^{7}$ The burgeoning crisis in the delivery of quality clinical care in rural communities has been underscored previously. Interestingly, IMG's have long been bridging this gap and providing essential healthcare services in these rural communities and serve as the core of care options available to this grossly underserved population. Therefore, the role of IMG's in the delivery of quality clinical care in the United States is incontrovertible and their ongoing valuable and vital contribution must not be underestimated.

\section{PROPOSED CHANGES - USMLE:}

A synopsis of the three proposed changes of significant magnitude announced by USMLE is provided in Table 1 . These proposed changes were recommended after USMLE invited deliberate public comment and in consultation with key stakeholders and organizations involved in the education and training of medical students and residents. The fundamental premise for recommending these changes was to continue to enhance both qualitative and quantitative assessment of student's performance to ensure that it meets the evolving needs of this profession.

\section{IMPACT OF THESE CHANGES ON IMG'S:}

Impact of the proposed changes have been outlined in many previous studies..$^{8}{ }^{11} \mathrm{~A}$ recent survey conducted by Bhukan T, et.al., to ascertain the impact of these changes on IMG's was very illuminating. ${ }^{12} \mathrm{~A}$ total of 417 students from various international medical schools responded to this survey. An abbreviated outcome of this survey is presented in Table 2.

The perception of IMG's as depicted by this survey is indeed alarming suggesting that the level of confidence among graduates of international medical schools to secure residency positions in the US has been undermined by proposed changes in various steps of USMLE. Additionally, this survey also underscored the enhanced recognition by the IMG's of the importance 


\begin{tabular}{cccc}
\hline Table 1: Current and proposed changes in various steps of USMLE & \multicolumn{3}{c}{ PROPOSED CHANGES } \\
\cline { 2 - 4 } & FIRST & SECOND & THIRD \\
\hline & $\begin{array}{c}\text { Reporting of USMLE } \\
\text { Step 1 will Change } \\
\text { from three-digit } \\
\text { Numeric Score to } \\
\text { PRoss/Fail }\end{array}$ & $\begin{array}{c}\text { Pass } \\
\text { USMLE Step 1 Before } \\
\text { USMLE Step 2 CS }\end{array}$ & $\begin{array}{c}\text { Number of Attempts } \\
\text { for Each USMLE Step } \\
\text { or Step Component } \\
\text { Reduced from } \\
6 \text { to 4 }\end{array}$ \\
\hline EFFECTIVE DATE & No Earlier than & March 01, 2020 & No Earlier than \\
& January 01, 2022 & January 01, 2021 \\
\hline
\end{tabular}

Table 2: Outcome of a survey conducted to ascertain the impact of changes in USMLE IMG's was very illuminating

\begin{tabular}{|c|c|c|c|}
\hline \multirow[b]{2}{*}{ QUESTION } & \multicolumn{3}{|c|}{ RESPONSE (\%) } \\
\hline & $\begin{array}{c}\text { STRONGLY } \\
\text { AGREE }\end{array}$ & $\begin{array}{l}\text { AGREE (NO } \\
\text { CHANGE) }\end{array}$ & DISAGREE \\
\hline $\begin{array}{c}\text { Change in scoring USMLE STEP } 1 \text { to pass/fail will } \\
\text { benefit the IMG's when applying for residency } \\
\text { programs in US as compared to domestic } \\
\text { graduates? }\end{array}$ & $39.6 \%$ & $4.8 \%$ & $55.6 \%$ \\
\hline $\begin{array}{c}\text { The three-digit numerical grade of USMLE Step } 1 \\
\text { give distinct advantage to IMG's vs domestic } \\
\text { graduates }\end{array}$ & $83.7 \%$ & $11.8 \%(4.5 \%)$ & $\mathrm{N} / \mathrm{A}$ \\
\hline $\begin{array}{l}\text { Applications from IMG's for residency in US will } \\
\text { be decreased as a result of proposed changes in } \\
\text { USMLE Step 1? }\end{array}$ & $10.6 \%$ & $51.3 \%(24.5 \%)$ & $12.2 \%$ \\
\hline $\begin{array}{l}\text { It will be more difficult for IMG's to secure a } \\
\text { residency position in subspecialties due to the } \\
\text { proposed changes in USMLE Step I exam? }\end{array}$ & $76 \%$ & $19.4 \%(4.5 \%)$ & $\mathrm{N} / \mathrm{A}$ \\
\hline $\begin{array}{l}\text { Due to these proposed changes in USMLE } \\
\text { examination, IMC's will have more confidence in } \\
\text { applying to Tier I residency programs? }\end{array}$ & $10.6 \%$ & $65 \%(12.9 \%)$ & $11.5 \%$ \\
\hline $\begin{array}{c}\text { Extracurricular activities will be viewed with } \\
\text { more importance in the applicant selection } \\
\text { process? }\end{array}$ & $69.9 \%$ & $24.8 \%$ & $5.3 \%$ \\
\hline
\end{tabular}

of research, scholarship and letters of recommendations in securing an interview in US residency programs. It will be incumbent upon all involved institutions and organizations engaged in evaluating graduates of domestic and international medical schools to continue to monitor the impact of these proposed changes in USMLE and to take timely and appropriate decisions to avert any undesirable outcome.
ACKNOWLEDGEMENT: The authors acknowledge the contribution by Annelyn Torres-Reveron, PhD., Clinical Research Scientist, Research Academy, the DHR Health Institute for Research and Development.

Received: August 23, 2020

Accepted: September 15, 2020 


\section{REFERENCES}

1. The National Residency Matching Program. Main residency match data and reports [Internet]. United States: NRMP International; 2020 [cited 2020 Aug 21]. Available from: http://www.nrmp.org/mainresidency-match-datal

2. USMLE. Change to Pass/Fail Score Reporting for Step 1 [Internet]. United States: Federation of State Medical Boards (FSMB) and National Board of Medical Examiners ${ }^{\circledR}$ (NBME $\left.{ }^{\circledR}\right)$; [cited 2020 Aug 21]. Available from: https://www.usmle.org/incus/

3. USMLE. United States Medical Licensing Exam ${ }^{\circledR} .1$ [Internet]. United States: Federation of State Medical Boards (FSMB) and National Board of Medical Examiners ${ }^{\circledR}$ (NBME®); [cited 2020 Aug 21]. Available from: https://www.usmle.org/

4. Dall T. The complexities of physician supply and demand: Projections from 2016 to 2030. IHS Markit Limited; 2018.

5. The Medicus Firm. 2018 Physician Practice Preference \& Relocation Survey [Internet]. [cited 2020 Aug 21]. Available from: https://www.themedicusfirm.com /physician/annual-practice-survey/

6. Ahmed AA, Hwang WT, Thomas CR Jr, Deville C Jr. International Medical Graduates in the US Physician Workforce and Graduate Medical Education: Current and Historical Trends. J Grad Med Educ 2018; 10:214-8. doi:10.4300/JGME-D-17-00580.1
7. Association of American Medical Colleges. Total U.S. Medical School Graduates by Race/Ethnicity (Alone) and Sex, 2014-2015 through 2018-2019 [Internet]. [cited 2020 Aug 21]. Available from: https://www. aamc.org/system/files/2019-11/2019 FACTS Table B4.pdf

8. Choudhary A, Makhoul AT, Ganesh Kumar N, Drolet BC. Impact of Pass/Fail USMLE Step 1 Scoring on the Internal Medicine Residency Application Process: a Program Director Survey. J Gen Intern Med 2020; 1-2. doi:10.1007/s11606-020-05984-y

9. Boulet JR, Pinsky WW. Reporting a Pass/Fail Outcome for USMLE Step 1: Consequences and Challenges for International Medical Graduates. Acad Med. 2020;95: 1322-4. doi:10.1097/ACM.0000000000003534

10. Kalyoussef E, Dhanda AK, Paskhover B. Implications of Change to USMLE Step 1 Scoring for Otolaryngology Residency Programs. Otolaryngol Head Neck Surg 2020;194599820936631. doi: $10.1177 / 0194599820936631$

11. Huq S, Khalafallah AM, Botros D, Jimenez AE, Lam S, Huang J, et al. Perceived impact of USMLE Step 1 pass/fail scoring change on neurosurgery: program director survey. J Neurosurg 2020;1:1-8.

doi: $10.3171 / 2020.4$.JNS20748

12. Bhukan T, Rao RS, Martinez F, Lavespere G. What effect do you think the new Pass/Fail system will have on international medical graduates? Senior Medical School Project, St. George's University, School of Medicine 2020. 